\title{
Ethics watch
}

\section{DIRECT-TO-CONSUMER GENOME SCANNING SERVICES. ALSO FOR CHILDREN?}

At least five companies currently offer personal genome-scanning services: 23 andMe, deCODE (with the service deCODEme), Navigenics, Gene Essence and SeqWright. These services include offering information regarding susceptibility to disease (for example, common complex disorders such as prostate cancer or type 2 diabetes) and to non-disease traits (for example, bitter-taste perception or nicotine dependence).

An analysis of the above-mentioned companies' web sites, including informed consent forms, reveals that their policies differ regarding the testing of minors. Navigenics and Gene Essence refuse to process samples originating from minors. The remaining three companies, however, accept that minors can be tested. deCODE writes: "[...] either you are the owner of the sample or have full authority of the owner or subject of the sample to submit the sample for processing." ${ }^{1}$ On its web site SeqWright states: "I am at least 18 years of age OR I am the legal guardian of the client (if the client is younger than 18 years old or unable to sign below)."2 23andMe writes: "You represent that you are eighteen (18) years of age or older. You are guaranteeing that the sample you provide is your saliva; if you are completing this consent form on behalf of a person for whom you have legal authorization, you are confirming that the sample provided will be the sample of that person." ${ }^{3} 23$ andMe adds that: "Neither 23andMe nor any of its services are designed or intended to attract children under the age of 13. A parent or guardian, however, may order and set up an account for our services on behalf of his or her child. The parent or guardian assumes full responsibility for ensuring that the information that he/she provides to 23andMe about his or her child is kept secure and that the information submitted is accurate." ${ }^{\prime 4}$

Various reasons could explain why these companies allow minors to be tested, usually via parents who provide a saliva sample of their children for a personalized genome scan. First, motivating whole families to purchase their services is financially more interesting than only targeting individuals. Second, these companies clearly emphasize that their services are a risk-assessment tool and are not clinical services that should be used as the basis for making medical decisions. 23andMe emphasizes, for example, that: "[their] service content is not to be used, and is not intended to be used, by you or any other person to diagnose, cure, treat, mitigate, or prevent a disease or other impairment or condition, or to ascertain your health." ${ }^{5}$ Therefore, the ethical concerns that are linked to predictive and carrier testing of minors might not be applicable in this context. Third, the provision of personalized genetic information to adults is considered as a way to educate them about the role of genetics in determining whether they will develop a specific disease or condition. 23andMe, for example, believes that: "[...] giving personalized genetic information to our customers can inspire them to take more responsibility for their own health and well-being." ${ }^{6}$ If adults can benefit from this information, why should parents not be able to take care of this risk information for their children and incite them to follow a healthier lifestyle? Fourth, both deCODE and 23andMe have developed a tool that allows consumers to share and compare individual genetic information with that of family and friends. Although both acknowledge that the choice to share this information with friends, family members or other individuals should be made carefully, the ability to share this information within the family unit is not considered a problem. As 23 andMe states: "We believe that the potential benefits of sharing genetic information outweigh the privacy risks." 7 deCODE also makes available a family registration form that gives consumers a discount on the purchase of their service.

One of the most striking aspects of allowing parents to submit samples from their children is that this denies some of the strongest claims continuously made by these companies. It ignores the fact that: "[...] your genetic information is extremely sensitive. In fact, it may be the most sensitive information there is and as new discoveries are made, and more is learned about what your genes say about you, this information is likely to become evermore sensitive over time." ${ }^{\prime}$ Performing these tests on children is ignoring the sensitive character of that information for these children. Moreover, it undermines the claim that: "[...] the only people who should be able to see your genetic information are you and those with whom you choose to share it." If individuals are tested as children, they are not able to choose whether they want to share this information with their parents. Finally, the concerns that genetic information might lead to misuse by third parties also applies in this context.

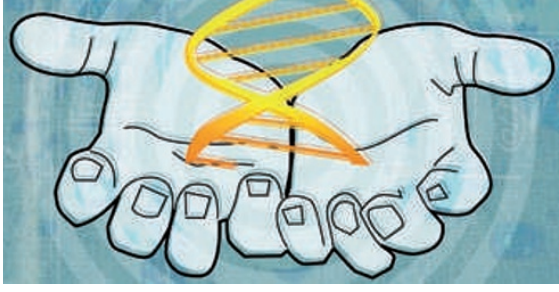

Based on these considerations, we question why these companies continue to accept requests to process samples from minors. The practice of personal genome-scanning services should be brought in line with existing recommendations, guidelines and regulations that apply to the clinical genetics setting. It was precisely these "ethical, privacy and informed consent considerations regarding genetic testing of minors for predisposition or carrier status of adult-onset genetic disorders" ${ }^{10}$ that led Navigenics to decide not to process samples or information from individuals under the age of 18 .

In conclusion, we recommend that these companies endorse Article 4 of the suggested code of practice already advanced in 1997 by the Advisory Committee on Genetic Testing (UK), which states: "Genetic testing services supplied direct to the public should not be supplied to those under the age of 16 , or to those unable to make a competent decision regarding testing." ${ }^{11}$

Pascal Borry*, Heidi C. Howard ${ }^{\ddagger}$, Karine Sénécal ${ }^{\ddagger}$ and Denise Avard ${ }^{\ddagger}$

${ }^{\star}$ Centre for Biomedical Ethics and Law, Katholieke Universiteit Leuven, Kapucijnenvoer 35, 3000 Leuven, Belgium

${ }^{\ddagger}$ Centre de Recherche en Droit Public Université de Montréal, C.P. 6128, succ. Centre-ville Montréal, Québec H3C 3J7, Canada

Correspondence to P.B. email:Pascal.Borry@med.kuleuven.be
REFERENCES ${ }^{1}$ Service agreement and informed consent. deCODEme [online], <http://www.decodeme.com/ information/service agreement > (accessed 20 Oct 2008)| ${ }^{2}$ Personal information and acknowlegement form. SeqWright [online], <https://gps.seqwright.com/orderform.php> (accessed 20 Oct 2008)| $\left.\right|^{3}$ Consent and legal agreement. 23andMe [online], https://www.23andme.com/about/ consent (accessed 20 Oct 2008)| ${ }^{4}$ Privacy statement. 23 andMe [online], <https://www.23andme.com/about/ privacy $>$ (accessed 20 Oct 2008) | $\left.\right|^{5}$ Terms of service. 23 andMe [online], https://www.23andme.com/about/tos (accessed 16 Oct 2008) | ${ }^{6}$ For physicians. 23 andMe [online], https://www.23andme.com/for/physicians (accessed 20 Oct 2008)|'Policy forum. 23 andMe [online], https:// www.23andme.com/about/policy (accessed 21 Oct 2008)| ${ }^{8}$ Privacy statement. SeqWright [online], http://www. seqwright.com/gps/privacy.php (accessed 20 Oct 2008)| ${ }^{9} T$ The deCODEme concept. deCODEme [online], http://www. decodeme.com/index/about concept (accessed 20 Oct 2008) | ${ }^{10}$ Privacy protection. Navigenics [online], http://www. navigenics.com/policies/Privacy (accessed 21 Oct 2008)| ${ }^{11}$ Advisory Committee on Genetic Testing. Code of Practice and Guidance on Human Genetic Testing Services Supplied Direct to the Public. London: Health Departments of the United Kingdom. [online], < http://www.dh.gov.uk/en/ Publicationsandstatistics/Publications/
PublicationsPolicyAndGuidance/DH 4005565>(1997) 